\title{
Receptiveness and Humanization from the Perspective of Anesthesiologists
}

\author{
Maria de Fátima Oliveira dos Santos ${ }^{1}$, Maria das Graças Melo Fernandes ${ }^{2}$, Harison José de Oliveira ${ }^{3}$
}

\begin{abstract}
Summary: Santos MFO, Fernandes MGM, Oliveira HJ - Receptiveness and Humanization from the Perspective of Anesthesiologists.
Background and objectives: Receptiveness is a tool that brings contributions for health care humanization, especially with regard to its practice in the field of Anesthesiology. The aim was to investigate through the report of anesthesiologists the understanding of the receptiveness phenomenon among these professionals.
\end{abstract}

\begin{abstract}
Methods: This is a descriptive qualitative research held at the Hospital Universitário Lauro Wanderley (HULW), in the city of João Pessoa, PB. The sample consisted of 16 attending anesthesiologists, $25 \%$ female doctors and $75 \%$ male doctors. Data were collected through interviews guided by two semi-structured questions from September to October 2010. Data analysis was performed using the technique of Collective Subject Discourse (CSD).

Results: The anesthesiologists' answer to the following question was considered as this study's result: "What do you think about the practice of receptiveness as a strategy to humanize the doctor-patient relationship?" The doctors' CSD presented two central ideas: 1) a holistic approach to the patient; 2) a strategy that improves the doctor-patient relationship. When asked about the strategies adopted by them to humanize the relationship with the patient at the time of reception, their reports were organized based on three central ideas: 1) observation of patients' rights; 2) therapeutic communication; 3 ) preanesthetic visit. It was found that the physicians involved in the research recognized the value of receptiveness as a strategy to humanize the doctor-patient relationship.
\end{abstract}

Conclusions: The receptivity to the patient in the course of anesthesia is very important because it allows the professional to perform a qualified hearing of the patient's history, together with the humanized care process, which enables the improvement of the interaction between doctor and patient.

Keywords: Altruism; Anesthesiology; Delivery of Health Care; Humanism; Physician-Patient relations.

(C2012 Elsevier Editora Ltda. All rights reserved.

\section{INTRODUCTION}

The progress of science in the various sectors of activity has been fairly successful regarding material progress, but the great difficulty lies in the most important, the human being. As in other sciences, medical science started to realize the need for improved doctor-patient relationship. But what is the ideal model for the doctor-patient relationship? There is no ideal model, except in theory, but surely the model to be adopted must have the patient as the main goal.

Received from the Universidade Federal da Paraiba. Work extracted from the dissertation "Receptiveness as a strategy to humanize the anesthesiologist and the SUS users relationship", presented for the Graduate Program in Nursing at the Universidade Federal da Paraíba (UFPB), Brazil.

1. Master in Public Health; PhD student in Bioethics, Faculdade de Medicina da Universidade do Porto, Portugal; Anesthesiologist, Hospital de Emergência e Trauma Senador Humberto Lucena; Professor, Faculdade de Medicina Nova Esperança (FAMENE)

2. PhD, Nursing; Professor, Undergraduate and Post-Graduate Nursing Course, Universidade Federal da Paraíba (UFPB)

3. Diploma in Anesthesiology; Anesthesiologist, Hospital de Emergência e Trauma Senador

Humberto Lucena e do Hospital Santa Isabel

Submitted on May 10, 2011.

Approved on August 3, 2011.

Correspondence to:

Dra. Maria de Fátima Oliveira dos Santos

Av. Umbuzeiro 881, apto 501

Manaíra

58038182 - João Pessoa, PB, Brazil

E-mail: fatimadeosantos@ hotmail.com
Because health care is a very complex system of activities, the Sistema Único de Saúde (SUS), guided by principles of universality, equity, and comprehensiveness requires modifications in the process of organizing the work of the professionals involved to cope with the problems of its users, generating creative actions to humanize health care at different levels of complexity. From the perspective of humanization, the patient should be seen as a whole person, making it necessary to change the focus from attention to the disease to comprehensive care to the patient, considering the uniqueness of his dimension as a subject ${ }^{1}$.

Thus, the Ministry of Health launched the National Policy of Humanization (NPH) to act in the organizational principles of health services, which must be patient-centered and provide care to all people. The NPH stressed the importance of humanizing the relationship between patient and health professionals, with receptiveness as a device to provide changes in health practices that need to be designed to meet the needs of patients and involve them effectively in the process of care ${ }^{2}$.

According to Ferreira et al. ${ }^{3}$, receptiveness to the user of health care service requires attention, respect and empathy by professionals in addition to mutual responsibility for the promotion of overall well-being. It is worth noting that in the welfare policy of SUS, receptiveness is noteworthy at all levels of care. 
Corroborating this assertion, Grosseman et al. ${ }^{4}$ highlight the importance of a qualified hearing in receptiveness, as this tool is a special process of human interaction - a strategy that works for building a doctor-patient relationship based on the technical, humanistic, and ethical dimensions.

In the anesthetic care, the primary benefit of the receptiveness provided by the anesthesiologist is, among others, the opportunity to answer the patient's questions regarding the procedure and their fears about anesthesia, thus initiating a communicative and therapeutic process. Caprara et al. ${ }^{5} \mathrm{em}$ phasize that the models of communicability are related to the therapeutic space and patient aspects, such as symptoms, expectations, fears, anxieties, and stress. Thus, at every preanesthetic visit, a new relationship between the patient and the anesthesiologist can be established.

In this line of thought, Neves et al. ${ }^{6}$ emphasize that receptiveness (used as an attitude and practice in health care activities and facilities management) "encourages relationship building, trust, and commitment of users with heath teams and services, helping to promote a culture of solidarity and the legitimacy of the public health system". On the other hand, the authors report that despite the progress and achievements of this system, there are still gaps in the care and management models of services regarding the user's access and the way they are met.

Proposals for humanization in health care indicate the need for progress in considerations about receptiveness as a device for humanization and, therefore, committed to the inseparable considerations and ethical aspects that "range from the recognition of health as a right to issues involving the accountability and bound relationships established between the protagonists of health care and the health management" 7 .

Silva et al. ${ }^{8}$ reinforce that receptiveness "does not act as an isolated action, but as a process that combines several actions, which requires a meeting between the professional subject and the demanding subject in a humane and effective way". Mehry ${ }^{9}$ emphasizes that receptiveness generates humanized relationships between those who care and those who are cared for, as it is an indispensable technological tool in health care. The incorporation of receptiveness (as a lighter technology in health care by workers in this field) tends to settle a quality work with more horizontal relationships.

The aim of this study was to investigate the understanding of anesthesiologists about the phenomenon of receptiveness.

\section{METHODS}

Exploratory, descriptive study with qualitative approach performed at Hospital Universitário Lauro Wanderley (HULW), in the city of João Pessoa, PB. The sample consisted of 16 attending anesthesiologists in the operating room at HULW who agreed to participate.

Table I shows the characteristics of participants and the variables: gender, time since graduation, post-graduation, and time in the field of Anesthesiology. Of the total sample, $25 \%$
Table I - Qualifying Characteristics of the Study Participants. João Pessoa-PB, 2010

\begin{tabular}{lll}
\hline Variable & Sample $(\mathrm{n}=16)$ & \\
& $\mathbf{n}$ & $\%$ \\
\hline Sex & 4 & \\
Female & 12 & 25.0 \\
Male & & 75.0 \\
Time since graduation (years) & 1 & \\
$10-15$ & 4 & 6.0 \\
$15-20$ & 3 & 25.0 \\
$20-25$ & 1 & 19.0 \\
$25-30$ & 7 & 6.0 \\
$30-35$ & & 44.0 \\
Post-Graduation & 16 & \\
Anesthesiology & 1 & 100.0 \\
Clinical Medicine & 1 & 20.0 \\
Family Medicine & 1 & 20.0 \\
Occupational Medicine & 2 & 40.0 \\
Acupuncture & & \\
Time since Post-graduation (years) & & 6.0 \\
$5-10$ & 1 & $\mathbf{4 4 . 0}$ \\
$15-20$ & 7 & 6.0 \\
$20-25$ & 1 & 13.0 \\
$25-30$ & 2 & 31.0 \\
$30-35$ & 5 & \\
\hline
\end{tabular}

Research data, João Pessoa, 2010.

were female and $75 \%$ were male. Regarding the time since graduation they mostly had between 30 and 35 years, which showed that the anesthesiologists surveyed had had a long period of medical practice. As for the engagement of professionals in postgraduate courses, besides all having specialty in Anesthesiology, a mandatory condition for the practice, two were also specialized in acupuncture, one in occupational health, one in family medicine, and one in clinical medicine.

Data were collected through semi-structured interviews, by appointment, which were recorded and later transcribed after obtaining the signed informed consent. Following the steps of the empirical data transcription obtained from interviews, systematic and targeted readings of the material were performed. For data analysis, the method of the Collective Subject Discourse (CSD) proposed by Lefevre et al. ${ }^{10}$ was used, which comprises a set of individual lines taken from the central ideas for building a speech synthesis that represents the collective thinking and seeks to clarify the social representation of a given phenomenon.

This study was approved by the Ethics Committee of the Hospital Universitário Lauro Wanderley, Universidade Federal da Paraíba (UFPB), under protocol No. 396/10.

\section{RESULTS}

\section{Question 1}

The questions posed in the study were analyzed qualitatively. In response to the first question: "What do you think about the practice of receptiveness as a strategy to humanize the 
doctor-patient relationship?" The CSD of the doctors involved in the study guided their lines around two central ideas: 1) a holistic approach to patient; 2) a strategy that improves the doctor-patient relationship (Table II).

\section{Question 2}

In response to the second question: "What are the strategies you adopt to humanize your relationship with the patient at the time of receptiveness?" The CSD of anesthesiologists was organized based on three central ideas: 1) observation of patients' rights, 2) therapeutic communication, 3) and preanesthetic visit (Table III).

\section{DISCUSSION}

Regarding Question 1, the Central Idea 1 (a holistic approach to the patient), the study participants believe that this strategy works when the patient is seen as a whole person. Although holism is a jargon widely known in the field of health, the patient is often reduced to the physical aspect, usually considering only the material dimension of his body, thus making it an object of affection. Nevertheless, the participants' collective subject discourse states the importance of comprehensive care for the person and indicates the actual realization of this care, as evidenced in the following report:

[...] The practice should be humane, treating the individual as a human being within his social, psychological, and economic contexts.

[...] Humanize is to treat the human being as a person who has a conscience, who has other needs besides a diseased liver, a broken leg; it is to treat him as a human being who has family, who has a job, doubts, and vulnerabilities.

As noted, the collective subject discourse of the interviewed physicians regarding their understanding of holistic care correlates with the understanding of Leite et al. ${ }^{11}$ about the phenomenon: "[...] vision of the human being within a biopsychosocial context, as a singular being, who has his own

Table II - Central Idea and Collective Subject Discourse in Relation to the Question:

What do you think about the practice of receptiveness as a strategy to humanize the doctor-patient relationship?

Central Idea - $1 \quad$ Collective Subject Discourse

Humanization, as its name implies, is treating the patient well, a good history-taking, always be present at his side, watching the monitor, pulse, pupils, mucosa, and perfusion of the patient. In case of anesthesia, you have to be there. Always observing the patient's clinical conditions, listening to the patient, always vigilant. Vigilance is important [...]The practice should be humane, treating the individual as a human being within his social, psychological, and economic contexts [...]Humanize is to treat the human being as a person who has a conscience, who has other needs besides a diseased liver, a broken leg; it is to treat him as a human being who has family, who has a job, doubts, and A holistic approach to vulnerabilities [...]To me, humanize is to treat the person better, provide human care, and not treat the person as a patient body piece, an illness, a leg [...]Treating the patient as a person, not as a number. Considering his disease, his pain, his anguish. [...] Receptiveness is to humanize care [...] assisting with the soul, assisting with the spirit. Understand others. Listen to what the patient has to say, pay attention. [...]l think this is a set of practices, actions; it is to put the soul in the assistance. [...] Receptiveness is already a form of humanization. It is about welcoming and guiding the patient well. It's about holding idealism for the profession, be aware of the importance of your work before the anesthesia. We practice medicine because it is a vocation. I see the patient holistically, as a true individual who has a social context, a family, and who is at some place where he has no acquaintances.

Central Idea - $2 \quad$ Collective Subject Discourse

[...] Every patient is unique. I think that receptiveness has to exist for everyone. The practice of receptiveness is A strategy that improves very important to improve the relationship between physician and user. [...] The tranquility and confidence of the the doctor-patient patient contribute to the success of anesthesia induction. [...] The interaction between the healthcare professional relationship and the patient leaves the patient more relaxed [...] a necessary practice for closer doctor-patient relationship. [...] Receptiveness is essential for both the patient's relationship with the institutions and doctors. To me, humanization is to treat the patient with care, with dedication, promptness, with confidence and, above all, with respect. [...] It is a paradigm shift that will produce good results. It is the essence of medical practice, treating the patient as an equal, not as an object of work.

[...]You practice medicine in the certainty that you are dealing with another person, another human being. Medicine is a profession that is humanitarian par excellence, by nature. The earlier the receptiveness the better the doctor-patient relationship. Humanization is a combination of several factors: improving the doctor-patient relationship [...] Always putting yourself in the patient's shoes. It is what we call empathy. By putting himself in the patient's shoes, the doctor identifies what are his difficulties and what he can do to improve it [...], improve patient's pain [...]lt is dedication, attention. It's about having commitment to the person who is in need, apply what you learn, the best to the person who is on your side. I think that improves the doctor-patient relationship. That's it! [...] Approaching! You start respecting the patient in this regard. Respect for the patient. [...] I think it's very important to respect the patient [...] 
Table III - Central Idea and Collective Subject Discourse in Relation to the Question:

What are the strategies you adopt to humanize your relationship with the patient at the time of receptiveness?

\begin{tabular}{ll}
\hline Central Idea - 1 & Collective Subject Discourse \\
\hline & $\begin{array}{l}\text { I treat all patients equally [...], we should welcome the patient precisely for humanitarian purposes. I try to treat him } \\
\text { with all the respect and care, making him very comfortable [...] so when the patient seeks the public health, he will find }\end{array}$ \\
Observation of patient & $\begin{array}{l}\text { everything that should be given to a human being (love, care, ethics) all for the sake of the patient's health. [....] The } \\
\text { rights }\end{array}$ \\
$\begin{array}{l}\text { attention given to SUS user has to be in a humane way. These users really [...], as I said, are fragile [...], emotionally } \\
\text { and physically fragile. The family is also out there waiting [...] mothers, parents who can not accompany the patient. } \\
\text { These people are very vulnerable in all aspects. They need us as doctors, as citizens, as agents who deal with human } \\
\text { beings. }\end{array}$
\end{tabular}

Central Idea - $2 \quad$ Collective Subject Discourse

Taking good care of the patient, listening to him, clarifying all his doubts, reassuring about the procedure, so that he will arrive at the operating room more relaxed... I say something nice about the patient. I say it will be all right, I tell a joke, I ask him to breathe ten times, perform a relaxation. I identify myself to the patient. I listen to his complaints; I try to understand his suffering, ask what he is feeling. I try to reassure the patient, putting myself at his disposal to meet Therapeutic his needs [...] I enter the patient's room smiling, making him more relaxed. [...] I try to be receptive, provide maximum communication comfort, and give information to both patients and family members. [...] I show the client that I am there as a human being, not as a cold professional! A technician! I act in a joyful manner, I don't think about the outside problems, or personal problems, or professional problems. [...]l use words that he can understand, and not be surprised by the environment in which he is placed at the moment. [...] The patient says thank you, which is very good. I pay attention to the person. [...] I try to improve the doctor-patient relationship, talking to the patient, giving information.

Central Idea - 3 Collective Subject Discourse

In the preanesthetic visit, I identify myself. We talk [...] receptiveness is talking to the patient about everyday things, so that the patient feel like an equal, everyone is equal. You try to answer questions, according to his educational level. You may not use technical language. I give orientation on the medication and fasting. Explain the reason for stopping the medication. [...] Patients are grateful [...] "Doctor, now l'm confident, now l'm more relaxed." The patient becomes more confident, more relaxed to go into the operating room. We anesthesiologists performed the receptiveness in the preanesthetic visit. I think receptiveness accounts for $30 \%$ of surgery. [...] The patient is confident; he goes more

Preanesthetic visit relaxed to surgery. We do a pre- and post-anesthetic evaluation. The preanesthetic visit is the first contact of the anesthetist to get to know the patient, to start the first contact. [...] The patient will want to ask about surgery. It is the time to clarify everything that he wants to know. [...]Provide clarification on the anesthetic procedure. The patient goes into surgery knowing you; he will arrive at the OR more relaxed and better accepted, knowing that his problem will be solved as best as possible, and with trust in the professionals. [...] The most important thing is giving psychological support. [...] I always identify myself when I arrive... First I call the patient by his the name [...] Good morning, or good afternoon, or good evening! A degree of empathy. Sometimes we even talk about matters other than surgery to make the patient more relaxed. I ask about his family, who is accompanying him, I ask about his fears and what is bothering him most. Sometimes patients are more afraid of anesthesia than the surgery. Sometimes, the surgery is huge but he is worried about the anesthesia, if he goes to sleep, if he will wake up, if his legs will move again. I love to hear people in the preanesthetic visit. It is of fundamental importance. The patient provides important information about the medication he is using, allergies. It is important for us anesthetists to know that. Wherever possible, I try to provide this receptiveness to our users. Politely, I try to reassure him, hear him, so that the patient has no fear of the procedure, fear of the unknown. In the preanesthetic visit, I identify myself [...], ask how he is doing. I deal with the patient as a person! As a human being! I give the necessary support. With this, you are helping someone. [...] Perform a real and updated consultation, unhurried, providing solution to the problem.

life story and his own values". To achieve this goal, Gallian ${ }^{12}$ stresses the need for a historical and philosophical reflection in order to humanize medicine and health sciences in general. Only a human care gives rise to a holistic approach.

From the perspective of comprehensive care, the focus should not be only on the individual's health problem, because it contradicts the proposal of humanization. Thus, the collective subject discourse of the professionals uses the light technologies of care to implement this service that involves the body and soul, as evidenced by the following excerpt:

[...] Assisting the patient with your soul, assisting with your spirit. Understand others. Listen to what the patient has to say, pay attention. I think this is a set of [...] practices, actions; it is to put the soul in the assistance.

Other aspects highlighted by anesthesiologists to humanize the doctor-patient relationship are: refer to the patient by his name, understand his concerns, discuss, inform, as evidenced by the following discourse:

[...] Treat the patient as a person, not as a number. Consider his disease, his pain, his anguish.

Extending this conception of the humanization process, Martins ${ }^{13}$ reports that this event begins with a proper understanding of the contemporary concept of health and wellness 
of the individual, promoted in all physical, mental, social, and spiritual dimensions.

In the discourse of anesthesiologists expressed in the Central Idea 2, one can note that they regard the phenomenon as a strategy that improves the doctor-patient relationship.

\section{[...] The practice of receptiveness is very important to improve} the relationship between doctors and users of the SUS [...].

[...] The interaction between the health care provider and the patient leaves the patient more comfortable, a practice necessary to strengthen the doctor-patient relationship [...].

Among the many factors that support the quality of this interaction, professionals stress the importance of encouraging the patient's feeling of confidence, an aspect that favors an uneventful anesthesia, as this speech makes clear:

\section{[...] The tranquility and confidence of the patient contribute} to a successful anesthetic process.

This statement reveals the importance of human conduct and solidarity as one of the fundamental assumptions in the humane medical assistance to the patient. It is worth emphasizing that health professionals should welcome patients in a kind, understanding, and friendly way, so that they feel valued and free to maintain an interpersonal relationship in which, based on empathy, trust, and accessible language, a healthy interaction is established.

Considering this fact, Ramos ${ }^{14}$ understands receptiveness as a posture that health professionals should develop through resolute actions. According to the author, receptiveness is a facilitator of the link between health professionals and users, providing greater adherence to treatment and better service organization.

Regarding Question 2, the Central Idea 1 (observation of patients' rights), anesthesiologists recognize the consideration of these rights as something important to humanize the doctor-patient relationship, particularly emphasizing the active listening to their problems and meeting their demands for care from the perspective of equality, as quoted below:

[...] I try to treat him with all the respect and care, making him very comfortable [...] so when the patient seeks the public health, he will find everything that should be given to a human being (love, care, ethics) all for the sake of the patient's health [...].

The Code of Medical Ethics has always focused on ensuring the rights of the patient, which requires among other guarantees considering the patient's autonomy ${ }^{15}$.

Corroborating this legal framework regarding the rights of the patient, the Ministry of Health published an official document, the Patient Rights Brochure in which it recommends that, under the care of SUS, the user is granted the following rights: access to treatment, respect and dignity, privacy and confidentiality, personal safety, identity, information, and consent ${ }^{16}$.
Regarding right to information, the physician, when talking to the patient, must demonstrate certainty and confidence, bearing in mind that he is entitled to clear, simple, and comprehensive information appropriate to his socio-cultural conditions.

It should be noted that, in general, modern medicine has stood back from the fundamental mission of considering the person being cared for (individual or collective) from the human perspective, and that should requires consideration by those in the profession, demanding sometimes a return to their origins where there was a greater appreciation for the person in their daily practice ${ }^{17}$.

Pasche ${ }^{18}$ sees receptiveness as a building of satisfactory response to the needs, bypassing the logic of services organization, which should have in the same receptiveness the ultimate ideal of performing its functional activity. Moreover, being an ethical guideline, it is non-negotiable and, therefore, a fundamental direction for the construction of care networks.

Regarding the Question for Central Idea 2 (therapeutic communication), the collective subject discourse of the interviewees emphasized the importance of this basic tool of care as a strategy to humanize their actions, as stated below:

[...] I say something nice about the patient. I say it will be all right, I tell a joke, I ask him to breathe ten times, perform a relaxation. [...] I identify myself to the patient. I listen to his complaints; I try to understand his suffering, ask what he is feeling. I try to reassure the patient, putting myself at his disposal to meet his needs [...]

[...] I enter the patient's room smiling, making him more relaxed.

[...] The patient says thank you, which is very good. I pay attention to the person. [...] I try to communicate with the patient, give information.

The therapeutic communication consists in the professional's ability on using his/her knowledge to help people living with each other, to adjust their selves to unchangeable facts, and to overcome obstacles and face their health issues ${ }^{19}$.

According to Ceneviva et al. ${ }^{20}$, when talking to the patient, the language used should promote a clear understanding, never escaping the truth, respecting the rhythm of the patient without producing despair or hurting his self-esteem.

Regarding the Central Idea 3 (preanesthetic visit), in the collective subject discourse of doctors involved in the study it is emphasized the use of preanesthetic care as a strategy to humanize care, because anesthesia often generates fear, many times greater than that of the surgical procedure itself. Thus, the statement of physicians surveyed highlights the importance of preanesthetic visit as an effective action to establish a dialogue between doctor and patient.

[...] In the preanesthetic visit, I identify myself. We talk [...] The preanesthetic visit is the first contact of the anesthesiologist to get to know the patient [...]

[...]You help to clarify the doubts, according to the cultural level of his language. You may not use technical language. I give advice on medication and fasting. 
Considering the role of the anesthesiologist in the process of receptiveness, Meneses ${ }^{21}$ highlights: prepare the patient, medical and psychological aspects; foresee possible difficulties; calm the patient; gain his cooperation and confidence; and prepare him for the surgery.

In this sense, the anesthesiologist must carefully observe every detail during the procedures, be aware that caution is necessary as well as prompt intervention and that it can lead to a reduction of errors, stand firm in his actions, be patient with the patient and his family, be empathetic, and put himself in other people's place. This means having as constant practice the humanization of care.

Safety in anesthesia is based on a careful clinical examination of the patient and planning the anesthetic technique to be used, aspects to be considered in the preanesthetic visit. On this occasion, it is also essential to provide all necessary explanations to the patient, including informing him clearly about the risks related to the adopted procedures.

Pre-anesthetic visit also involves determining the type of anesthesia that the patient will receive. This is not just a mechanical procedure, nor the preference of the anesthesiologist, but it is a clinical decision that considers the context and characteristics of each patient, his physical and mental conditions, diagnosis, physiological conditions, pharmacological influences, and type of operation he will be submitted to 22 .

According to Meneses ${ }^{21}$, the patient has the right to a preanesthetic evaluation, which is a non-transferable responsibility of the anesthesiologist. In this evaluation, the patient should be informed about the sequence of preoperative and postoperative periods, with details consistent with their level of cognitive development. In addition, the anesthesiologist should make a direct, simple, and straightforward approach about the risks, pain, discomfort, examination, and other aspects.

Considering the above, the American Society of Anesthesiologists (ASA) proposed (in 1987) the standards for preanesthetic care in order to standardize the evaluation of the patient, which should include review of medical records; interview with the patient; physical examination; laboratory tests; prior anesthesia, medications, and/or consultations with specialists. As a rule, the amount of additional tests should be guided by age, physical condition, comorbidities, and complexity of the procedure ${ }^{23}$.

Bisinotto et al. ${ }^{24}$ report that one of the most relevant effects of the elective pre-anesthetic evaluation was the reduction in the number of canceled surgical procedures, together with the decrease in the solicitation of preoperative tests. The authors also point out that there was a decrease of more than $50 \%$ in the number of laboratory tests and medical appointments when the responsibility for the surgical preparation was designated only to the anesthesiology service.

Thus, we can infer that the pre-anesthetic visit is a relevant tool for the performance of a receptive and humanized care by anesthesiologists, as well as for reducing morbidity and mortality resulting from surgical procedures.

\section{CONCLUSION}

The receptiveness to the patient in the course of anesthesia is very important because it allows the professional to perform a qualified hearing, together with a humanized care process, enabling improved interaction between doctor and patient. Under these considerations, it is worth to highlight that the data produced here reveal a reality that has been trimmed and translates experiences and knowledge acquired in a particular way, portraying the understanding of the receptiveness phenomenon by anesthesiologists, as well as these professionals' rationale on the operational of this approach to health care.

Frequently, the goal of a investigation process is to explain, assess facts and correlated issues to the study's object, exposing challenges and propositions with the present reality on sight. However, these are not the researchers' expectations in this work, as it does not provide systematic conclusions. It only introduces ideas and temporary considerations. The qualitative approach of the research undertaken in this composition has focused on understanding the phenomenon from the perspective of the subject and, therefore, the individual, not suitable for generalizations, but for a process of reflection that should be continued.

Once these observations are made, the phenomenon observed by researchers should be discussed. Anesthesiologists, professionals of great importance in addressing the health-disease process, especially for exercising a profession that involves vulnerable people needing care, indicate the importance of valuing a humanistic approach for treating these individuals, although in some cases they reveal that such approach is still held in a precarious way and needs to be improved.

Therefore, it is clear that there is a long way to go before reaching an optimal patient care, requiring a process of change that permeates the ethical issues related to reorientation of attitudes and practices that may generate receptiveness, humanization, and resolution in the health care system.

Despite the difficulties exposed, it became clear that receptiveness does have a great potential to reverse the current logic of health care, using tools that depend only on the willingness of professionals to build a new practice of humanized care.

Considering the specific practice of anesthesiologists, it should be noted that, once this medical specialty is linked to technical and scientific knowledge, the professionals need to strengthen the bonds established with those who participate in their care, so that they can experience a unique and friendly service without fear and concerns in the course of anesthesia.

It has become evident, through the collective subject discourse, that many anesthesiologists enrolled in the study are acquainted with receptiveness, as shown by their quotes permeated with terms related to that strategy, such as hearing, welcoming and referral.

We stress that the attitude of individual professionals, from the confidence conveyed to the adequate way to address the patient, along with the establishment of ties with him are essential to establish the receptiveness and humanization of 
care, effectively facilitating the construction of a new way of working in health. We also emphasize the experience on the part of researchers, making it appropriate to mention the different aspects and emotions that permeated the production of this study, in addition to the critical reflections raised during its construction.

This work was performed by many hands, especially the anesthesiologists, who welcomed this project. The meetings were unique and provided several exchanges of ideas and opinions, which resulted in a collective discourse that could not be fully unveiled in its entirety.
In conclusion, the study provides a new perspective regarding the valuation of the receptiveness as a tool of paramount importance to strengthen the bond between the anesthesiologist and his patient.

\section{ACKNOWLEDGMENT}

The authors thank the anesthesiologists of the Hospital Universitário Lauro Wanderley (HULW) for kindly accepting to participate in this research. 


\section{REFERÊNCIAS /REFERENCES}

1. Brasil. Ministério da Saúde - Áreas temáticas BVS MS Humanização. Publicações. Brasília; 2009.

2. Takemoto MLS, Silva EM - Receptiveness and changes in the nursing work process in healthcare units in Campinas, São Paulo, Brazil. Cad Saúde Pública. 2007;23(2):331-340.

3. Ferreira MLSM, Cotta RMM, Oliveira MS - Reconstrução teórica do cuidado para as práticas de saúde: um olhar a partir da produção de alunos de curso de especialização à distância. Rev Bras Educ Med. 2008;32(3):291-300.

4. Grosseman S, Stoll C - O ensino-aprendizagem da relação médicopaciente: estudo de caso com estudantes do último semestre do curso de medicina. Rev Bras Educ Med. 2008;32(3):301-308.

5. Caprara A, Rodrigues $J-A$ relação assimétrica médico-paciente: repensando o vínculo terapêutico. Ciênc Saúde Coletiva. 2004;9(1):139146.

6. Neves $\mathrm{CAB}$, Rollo $\mathrm{A}$ - Acolhimento nas práticas de produção de saúde. Ministério da Saúde. Secretaria de Atenção à Saúde. Núcleo Técnico da Política Nacional de Humanização (Série B. Textos básicos em Saúde). 2 ed. Brasília-DF; 2006.

7. Farias LC - Acolhimento na atenção básica: reflexões éticas sobre a atenção à saúde dos usuários [dissertação]. Florianópolis: Programa de Pós-Graduação em Saúde Pública da Universidade Federal de Santa Catarina; 2007.

8. Silva LG, Alves MS - O acolhimento como ferramenta de práticas inclusivas de saúde. Rev APS. 2008;11(1):74-84.

9. Merhy EE - Saúde: a cartografia do trabalho vivo. 3 ed. São Paulo: Hucitec; 2002. (Saúde em Debate, 145). ISBN: 85-271-0580-2.

10. Lefèvre F, Lefévre AM, Teixeira JJV - O discurso do sujeito coletivo: uma abordagem metodológica em pesquisa qualitativa. Caxias do Sul: EDUCS, 2000.

11. Leite TAAF, Strong $\mathrm{MI}-\mathrm{A}$ influência da visão holística no processo de humanização hospitalar. Mundo Saúde. 2006;30(2):203-214.

12. Gallian DMC - A (re) humanização da medicina. 2001. [Acesso em 10 set 2010]. Disponível em: [http://www.unifesp.br/dpsiq/polbr/ppm/ especial02a.htm].

13. Martins A - Visões do feminino: a medicina da mulher nos séculos XIX e XX. Rio de Janeiro: Fiocruz; 2004.

14. Ramos DD, Lima MADS - Acesso e acolhimento aos usuários em uma unidade de saúde de Porto Alegre, Rio Grande do Sul, Brasil. Cad Saúde Pública. 2003;19(1):27-34.

15. Conselho Federal de Medicina (CFM). Código de Ética Médica. 2010. [Acesso em 20 dez 2010]. Disponível em: http://www.portalmedico. org.br/novocodigo/integra 4.asp] 
16. Brasil. Ministério da Saúde - Acolhimento nas práticas de produção de saúde. 2 ed. Brasília; 2006.

17. Dantas Filho VP, Sá FC - O cuidado na prática médica. Mundo Saúde. 2009;33(2):189-194.

18. Pasche DF - Princípios do SUS e a humanização das práticas de saúde. Seminário a Humanização do SUS em debate. Vitória; 2008.

19. Pontes AC, Leitão IMTA, Ramos IC. Comunicação terapêutica em enfermagem: instrumento essencial do cuidado. Rev Bras Enferm. 2008;61(3):312-318.

20. Ceneviva R, Castro e Silva Jr. - O paciente cirúrgico: relação médico paciente. Medicina (Ribeirão Preto). 2008; 41 (3):252-258.

21. Meneses JAG. Dilemas bioéticos na prática da anestesia. Rev Bras Anestesiol. 2001;51(5):426-430.

22. França GV - Os deveres do cirurgião. 2000. [Acesso: 11/fev/ 2011]. Disponível em: http://www.ibemol.com.br/sodime/artigos/obrigacao_ meio_result.

23. Solca $M$ - Evidence-based preoperative evaluation. Best Practice \& Research Clinical Anaesthesiology, v.20, n.2, p.231-236,2006.

24. Bisinotto FMB, Pedrini Jr. M, Alves AAR, Andrade MAPR - Implantação do serviço de avaliação pré-anestésica em hospital universitário: dificuldades e resultados. Rev Bras Anestesiol. 2007; 57(2):167-176. 